chairman of the International Committee for Biochemistry which was set up at the first International Congress of Biochemistry at Cambridge in 1949, was elected an honorary member of the Council. Fol. lowing on the unanimous decision of the Assembly, a formal application has now been made on behalf of the Union for adherence to the International Council of Scientific Unions.

\section{British Universities Film Council}

The report of the British Universities Film Council for 1953-54 is the sixth since its foundation, which was largely due to the initiative of members of the University Educational Film Council of Cambridge. The Council has welcomed the Universities of Aberdeen and Manchester to ordinary membership, making this total now thirty-one; the Scientific Film Association has been admitted to associate membership. The report refers to a few of the many activities of the British Universities Film Council, one of which is the issue to all member institutions of a card index giving full particulars of $16-\mathrm{mm}$. films likely to be of use at some stage or other in teaching at university-level or research. This list is useful for preliminary reference purposes and gives, under subject headings, the titles of index films. Realizing that such a carefully prepared and comprehensive list may be of value to many people and organizations besides their members, the British Universities Film Council has made copies available to all who are interested. They may be obtained from the Catalogue Secretary, Royal Technical College, Glasgow.

\section{Health Education throughout the World}

The Fifth World Health Assembly, held in May 1952, made provision for the convening of an expert committee on the health education of the public. This committee held its first meeting in Paris during December 1953, and its report has now been published (Technical Report Series No. 89: Expert Committee on Health Education of the Public. First Report. Pp. 41. (Geneva: World Health Organization; London: H.M. Stationery Office, 1954.) 1 Swiss franc; 1s. $9 d$. net; 0.25 dollar). The committee tried to outline the way people learn, and the role of the educator in health programmes; to state the broad principles of programme planning, evaluation and organization ; and to describe the development and use of methods and media, and the desirable training of personnel. Particular attention has been given to the importance of the learner, the 'consumer' of health education; too often in the past health education activities have relied on the wide use of educational media with insufficient consideration of the people for whom they were intended. The report also contains examples of how actual health education campaigns have been carried out in rural, semi-rural and urban areas. It would be interesting to know whether health educators throughout the world gain more from these three short case-studies or from the detailed statement of general principles which forms the bulk of the report.

\section{Interaction in Effects of Plant Growth Substances}

VARIOUS interactions in the physiological effects of growth substances on plant development have been investigated and discussed by G. E. Blackman and R. C. Robertson-Cuninghame (J.Exp. Bot., 5, No. 14, $184 ; 1954)$. The interrelated effects of 3 -indolyl- acetic acid and sodium 2:4-dichlorophenoxyacetate on the growth and development of Lemna minor and Helianthus annuus have been investigated by means of multifactorial experiments, involving three to five levels of each compound. A clonal population of $L$. minor was maintained under constant conditions of light ( 550 foot-candles) and temperature $\left(25^{\circ} \mathrm{C}\right.$.) and the growth regulators were added to a phosphatebuffered culture solution $(p \mathbf{H} \cdot \mathbf{5} \cdot \mathbf{I})$ which was changed every two days. In the $H$. annuus experiments the compounds, in aqueous solution, were placed by means of a micro-pipette on the leaves of young plants grown in a greenhouse or in the open. Indolylacetic acid, at concentrations up to 25 p.p.m., increases the relative growth-rate of $L$. minor on either a dry-weight or frond-area basis. Sodium dichlorophenoxyacetate at 0.025 p.p.m. has little effeet on growth, but at and above concentrations of 0.2 p.p.m. growth is depressed. The ratio of frond area to total dry weight is increased by indolylacetic acid, but is depressed by the phenoxyacetate. In the presence of indolylacetic acid, more particularly at the higher levels, the relative inhibition of growth caused by sodium dichlorophenoxyacetate is reduced. Various results with Helianthus annuus are also described. The authors conclude that the results which they have obtained in these experiments cannot be explained on the concept of wholly additive effects. There is evidence that the compounds can mutually interfere in their actions, and it would seem that more than one mechanism is involved. Many of the results can be satisfactorily interpreted on the basis that the two compounds act on a common system and that they compete with one another ; but the results are not compatible with the postulate that the dichlorophenoxyacetic acid directly inactivates indolylacetic acid.

\section{Some Tungsten and Molybdenum Products}

Electro-Alloys, Ltd., 47-49 Brunel Road, Acton, London, W.3, have issued an attractive and informative illustrated catalogue of their tungsten and molybdenum products. The content is printed in three languages-English, French and Germanand covers the use of tungsten as a contact material, tungsten and molybdenum as lead-in-wires for glass to metal seals, tungsten welding electrodes for inert-gas arc welding, molybdenum tubes and rods, tungsten anodes for $\mathrm{X}$-ray tubes, tungsten and molybdenum heaters for vacuum metallizing plant and for other special components required for the electronic and associated industries. The technical and physical characteristics of the two metals are clearly stated; whereas both metals have high melting points, low coefficients of thermal expansion and relatively good electrical conductivities at room temperature, their mechanical properties differ in that tungsten cannot be turned, threaded or drilled.

\section{The British Gelatine and Glue Research Asso- ciation}

THE annual general meeting of the British Gelatine and Glue Research Association was held on December 8 at the Connaught Rooms, London, W.C.2. Mr. S. G. Hudson (Messrs. Richard Hodgson and Sons, Ltd.), chairman of council, was in the chair. In presenting the annual report, Mr. Hudson commented on the extent of the Association's scientific publications, and on the facilities now available to assist member firms. Mr. A. G. Ward, director of research, described how the original decision of the 